\title{
Comparative Proteomic Analysis of Responses to Pathogen Infection and Wounding in Fagus sylvatica
}

\author{
Cristina-Maria Valcu, ${ }^{, \dagger}{ }^{\dagger}$ Magno Junqueira, ${ }^{\ddagger}$ Andrej Shevchenko, ${ }^{\ddagger}$ and Katja Schlink ${ }^{\dagger}$ \\ Section of Forest Genetics, Technical University Munich, Freising-Weihenstephan, Germany, and Max Planck \\ Institute of Molecular Cell Biology and Genetics, Dresden, Germany
}

Received May 21, 2009

\begin{abstract}
Defense responses of Fagus sylvatica seedlings elicited by infection with the root pathogen Phytophthora citricola and root or leaf wounding were compared at local and systemic levels in differential display experiments using two-dimensional gel electrophoresis followed by homology-driven mass spectrometric identification of proteins. A total of 68 protein spots were identified representing 51 protein functions related to protein synthesis and processing, energy, primary and secondary metabolism, as well as signal transduction, stress and defense. Changes in the abundance of root and leaf proteins partly overlapped between plant responses to the different stressors. The response to pathogen infection was rather late, weak and unspecific and accompanied by adjustments of the energy and primary metabolism which suggested either a lack of recognition or a suppression of host's defense reaction by the invading pathogen. The response to wounding involved changes in the basal metabolism as well as activation of defense mechanisms. Both types of changes were largely specific to the wounded organ. Similarities between the defense mechanisms activated by root infection and root wounding were also observed.
\end{abstract}

Keywords: compatible interaction • stress • pathogen • proteomics • wounding

\section{Introduction}

Investigations of plant response to biotic and abiotic stressors in the last decades revealed the existence of plant defense mechanisms of high complexity. Plant response to stress is no longer regarded as a linear succession of independent events, rather as a network of overlapping inter-regulated events strongly influenced by plant growth and development ${ }^{1}$ as well as by environmental conditions. ${ }^{2}$ Crosstalk between the signaling pathways triggered by different stressors (e.g., pathogen attack and herbivores/wounding) has been widely documented. ${ }^{3}$ Disentangling such complex defense systems requires the investigation of plant reactions to different stressors in comparable conditions.

Compatible plant-pathogen interactions are established when the plants fail to recognize the pathogen or when the pathogen suppresses the defense reaction of the host and result in plant susceptibility to the given pathogen. The hosts usually mobilize basic unspecific defense mechanisms and pathogeninduced necrosis can trigger systemic acquired resistance (SAR). ${ }^{4}$ Although patterns of response to pathogen attack

* To whom correspondence should be addressed. Present address: Experimental Paediatric Cardiology, Department of Paediatric Cardiology and Congenital Heart Disease, German Heart Centre, Technical University Munich, Lazarettstrasse 36, 80636 Munich, Germany. Tel, 0049 (0)89 1218 2701; e-mail, valcu@wzw.tum.de.

${ }^{\dagger}$ Technical University Munich.

‡ Max Planck Institute of Molecular Cell Biology and Genetics. common to many species have been described, plant's defense reactions against the pathogen are largely host- and pathogenspecific. $^{5}$

Plant response to herbivores/wounding is as complex as the response to pathogens. Depending on the attack/wounding site, various parts of the plant respond differently, ${ }^{6}$ and the response is often species-specific. ${ }^{7}$ In response to herbivores/ wounding, plants can increase their direct resistance against herbivores (induced systemic resistance, ISR) ${ }^{8}$ or attract parasitoids or predators of the herbivores. ${ }^{9}$ The same effects can be induced in unharmed neighboring plants ${ }^{10}$ following perception of volatile organic compounds $(\mathrm{VOC})^{11}$ emitted by individuals under attack.

The aim of this study was to compare the plant response to infection by the root pathogen Phytophthora citricola and to wounding and to identify and characterize common and specific changes in protein expression patterns. Phytophthora is a genus of Oomycetes, of which more than 60 species have been described to date. ${ }^{12}$ Soil born species of this genus are involved in the Fagus sylvatica and Quercus sp. decline syndromes $^{13}$ and in the Ink Disease of Castanea sativa. ${ }^{14} P$. citricola is one of the most frequent Phytophthora species isolated from forest sites across Europe $\mathrm{e}^{13,14}$ and around the world ${ }^{15,16}$ and has a broad host range, from agricultural to tree species. Woody plant species from more than 20 genera establish incompatible (e.g., Eucalyptus calophylla, ${ }^{17}$ Theobroma cacao, ${ }^{18}$ Prunus dulcis ${ }^{19}$ ) or compatible interactions with this pathogen. ${ }^{20}$ P. citricola isolates have been morphologically and/or genetically divided into several groups, suggesting that 
they form a species or subspecies complex..$^{15,21,22}$ The virulence largely differs among types and isolate ${ }^{21}$ and plant susceptibility to infection varies between species and ecotypes ${ }^{23}$ as well as seasonally. ${ }^{24}$ The incidence of Phytophthora-mediated diseases is significantly increased when infection is associated with other environmental stressors ${ }^{14}$ like flooding, particularly when this occurs in the period of active plant growth. ${ }^{24-26}$

F. sylvatica is the most abundant and dominant broad leafed tree species in Central and Eastern Europe and is highly susceptible to Phytophthora cambivora, Phytophthora cinnamoni, P. citricola, ${ }^{24}$ Phytophthora kernoviae, Phytophthora gonapodyides, Phytophthora ramorum ${ }^{27}$ and Phytophthora cactorum. ${ }^{28}$ Among these species, P. citricola is particularly aggressive $^{28}$ and the morphological and physiological consequences of $F$. sylvatica root infection with this pathogen have been addressed in several studies. ${ }^{20,29,30}$ The intimate mechanisms of the plant-pathogen interaction are however, not known.

Proteomics emerged as a powerful tool for the study of plant's response to different stress factors, including plantpathogen interactions, ${ }^{5}$ plant-herbivores interactions and wounding. ${ }^{31}$ Investigations at the proteome level estimate the actual abundance of proteins and sometimes their isoforms and posttranslational modifications (PTM). ${ }^{32}$ Among the methods currently employed in proteomics studies, 2DE provides a reasonably good resolution and coverage of the proteome and is particularly useful for the identification of isoforms and PTM. We therefore undertook a differential expression approach to compare local and systemic changes induced in the proteome of $F$. sylvatica seedlings by infection with $P$. citricola and leaf or root wounding. A set of wound experiments was designed to allow the identification of different wound response patterns and the estimation of the degree to which they overlap with plant's response to root infection.

Because the genome of $F$. sylvatica is unknown and the availability of sequence information from closely related species in public databases is still limited, the conventional approach for the mass spectrometric identification of proteins separated by $2 \mathrm{DE}$ has also limited efficiency. ${ }^{33}$ Homology-driven protein identifications relying on de novo interpretation of peptide tandem mass spectra followed by sequence-similarity database searches have therefore been employed to confirm protein identification by conventional techniques and to further identify proteins if the stringent searches failed.

\section{Material and Methods}

2.1. Plant Material. F. sylvatica seeds (R0016812 FOD Gessertshausen, elevation: 540-600 m a.s.l.) were germinated on paper towels moistened with sterile distilled water in dark, at $10^{\circ} \mathrm{C}$. When roots reached approximately $1 \mathrm{~cm}$, the seeds were gradually transferred to normal light and room temperature in individual tubes containing sterile tap water (liquid system) or individual pots (soil system).

2.2. Experiment Design. To allow for a direct comparison of plant reaction following pathogen attack and wounding, infection and wounding experiments of $F$. sylvatica seedlings were carried out in parallel under similar conditions as described below and in Supporting Information 1, Figure S1.

2.2.1. Infection Experiments. Three months old $F$. sylvatica seedlings were infected with the root pathogen $P$. citricola in soil $\left(N_{\text {infected }}=207, N_{\text {control }}=70\right)$ and liquid system $\left(N_{\text {infected }}=\right.$ 90, $\left.N_{\text {control }}=90\right)$.
For experiments in soil system, a 1:1 peat/vermiculite mixture was used to ensure appropriate $\mathrm{pH}$ conditions $(4.4-5)$ for the pathogen development. ${ }^{13} P$. citricola was cultured on V8-juice agar plates and inoculation of plants was performed according to Jung et al. ${ }^{34}$ To stimulate zoospores production and release, the pots were flooded $1 \mathrm{~cm}$ above soil level for 6 days. When first symptoms of leaf wilting appeared in some plants, leafs were sampled from the remaining healthy looking plants. P. citricola was reisolated from infected roots on selective agar medium ${ }^{34}$ and verified in a PCR reaction using CITR1/CITR2 primers. ${ }^{35}$

For the experiments in liquid system, seedlings with two fully developed leaves were transferred for accommodation into 2 L containers (10-15 seedlings per container), in which the infection was performed. For inoculation, $7 \mathrm{~mm}$ diameter plugs were cut from the edge of a 5 days old $P$. citricola culture that was rinsed with sterile water for the past $24 \mathrm{~h}$ to remove nutrients and stimulate zoospore formation. Containers were inoculated with 1 plug per plant; control plants received plugs from noninoculated plates treated as the $P$. citricola culture. Sampling was performed at two stages of infection: early (3-24 h) and late, at the appearance of first symptoms of root tip browning (4-6 days). Root infection was verified as above. The infection experiment in liquid system was repeated in the subsequent year for validation of 2DE results.

For 2DE, proteins were extracted from $P$. citricola grown in liquid medium. ${ }^{36}$

2.2.2. Wounding Experiments. Three months or 1 year old F. sylvatica seedlings were subjected to wounding experiments under different experimental setups in order to distinguish wound response patterns depending on the wounded organ. Leaf wounding was performed with a cork borer of $15 \mathrm{~mm}$ diameter; the leaf discs thus obtained were used as control samples. Roots were wounded using scissors. Samples were harvested at $3 \mathrm{~h}$ after wounding.

Local and systemic (leaves) plant response to leaf wounding was investigated in three month old plants grown in soil system $(N=40)$. The systemic response was also compared for leaves above and below the wounded leaf using 1 year old plants grown in soil $(N=57)$. Seedlings response to volatile signals was investigated in plants that "witnessed" the wounding of neighboring plants $(N=30)$. The systemic (at leaf level) and local (at root level) response to root wounding was characterized for plants grown in liquid system $(N=20)$, which allowed a "stress free" access to the root samples.

2.3. Protein Extraction and Separation. Leaf samples were harvested with a $15 \mathrm{~mm}$ cork borer while roots where gently blotted dry and cut with a scalpel. All plant material was frozen in liquid nitrogen within $30 \mathrm{~s}$. Each sample consisted of equal amounts of plant material pooled from several individuals (10-15 individuals for the experiments in liquid system and 35 for experiments in soil system). Each sample was harvested in duplicate; the duplicates were processed independently as technical replicates.

Sample preparation and separation by means of 2-DE was performed according to previously optimized protocols ${ }^{37,38}$ (detailed protocols in Supporting Information 1).

Proteins with low solubility were separated by SDS-PAGE in 15\% $1 \mathrm{~mm}$ thick gels, using Laemmli's buffer system. Six micrograms of protein was loaded per lane and gels were stained with silver following the same protocol as for the $2 \mathrm{DE}$ gels.

B Journal of Proteome Research - Vol. xxx, No. xx, XXXX 
2.4. 2DE Image Analysis. Gels were scanned under blue light at $300 \mathrm{dpi}$, with ImageScanner (GE Healthcare). Onedimensional SDS-PAGE gels were analyzed with ImageQuant 5.2 (Molecular Dynamics). 2DE spot identification and quantification were performed with Progenesis SameSpots (Nonlinear Dynamics).

Additional controls were designed in order to distinguish $P$. citricola protein spots among the spots up-regulated or induced on the 2-DE gels of the infected root samples. 2DE analysis of different developmental stages of Phytophthora palmivora revealed that only approximately $1 \%$ of proteins are specific to a particular stage. ${ }^{39}$ We therefore considered $P$. citricola grown in liquid culture an appropriate control for identifying the majority of proteins expressed by the pathogen. For this, samples of $P$. citricola grown in liquid culture were processed and separated on 2-DE gels in parallel with the F. sylvatica samples. To ensure the correct assignment of spots to the $P$. citricola or F. sylvatica proteome, a 1:1 mixture of their protein extracts was separated in parallel and matched with the individual gel samples.

Out of the protein spots that appeared as up-regulated or induced in the root samples particularly during the late stages of infection, 86 spots (50 on the acidic $\mathrm{pH}$ gradient and 36 on the basic pH gradient) clearly matched spots of the $P$. citricola proteome, all of them prominent spots both on the $P$. citricola gels and on the $F$. sylvatica/ $P$. citricola $2-\mathrm{DE}$ gels and were therefore eliminated from further analyses.

2.5. Data Analysis. 2.5.1. Selection of Differentially Expressed Proteins. Spot volumes normalized per gel were exported and $z$-scores were computed per gel in order to compensate for small between-gels variation due to differences in protein load and/or staining. All statistical analyses were performed with R2.4. $0^{40}$ using the following packages: clValid $^{41}$ $v c d,{ }^{42}$ effects $^{43}$ and nlme. ${ }^{44}$

The selection of differentially regulated 2DE spots was based on two criteria. First, differences in protein abundance were assessed between control and treated samples using $t$ tests (paired $t$ tests in case of samples originating from the same plants, as in the wound experiment) or linear mixed effect models ${ }^{45}$ (for nested designs as in the infection experiment in liquid system) with the $z$-scores of spot normalized volume as dependent variable, and the runs nested in samples as random factors. Second, the protein spots that exhibited statistically significant differences between the control and treated plants were subjected to further statistical investigation in order to establish if the observed fold variation could originate solely from biological and/or experimental variation.

For this, the level of spot volume variation that can occur by chance alone between biological replicates was expressed as the $95 \%$ quantile of the fold regulation distribution estimated for each spot based on pairs of two replicates randomly chosen form a pool of six independent biological replicates. This quantile was used together with each spot's parameters to calculate spot-specific levels of intrinsic variation (Supporting Information 1, Predictors of spot volume variation, and Figures S4, S5), used as thresholds above which differences in spot volumes between control and treated samples can be considered to represent protein expression regulation in response to stress.

2.5.2. Cluster Analysis. Clustering was based on the fold regulation of protein spots across all treatments. The clustering method was selected using clValid package. ${ }^{41}$ Proteins were clustered by hierarchical clustering based on a similarity matrix calculated using Pearson correlation coefficient. Clusters and heat maps (Supporting Information 1, Figure S6) were built with vcd package ${ }^{42}$ using the fold regulation values for each protein and treatment, respectively. The fold regulation values were positive for the up-regulated proteins and negative for the down-regulated proteins and were standardized per protein on a scale $[-1,1]$. Values corresponding to proteins which did not satisfy both the threshold and the significance criteria were replaced with " 0 ". In the clustering were included all proteins found to be regulated (both criteria satisfied) following any of the applied treatments as well as four proteins that satisfied the threshold criterion and exhibited marginally significant differences in their abundance following several treatments. The cluster also included four protein spots with marginally significant regulation, suspected to be isoforms of neighboring spots already selected as being regulated following one of the applied treatments.

2.6. Protein Identification by Mass Spectrometry. Protein spots were excised from preparative gels, reduced, alkylated, and in-gel digested with trypsin. ${ }^{46}$ Wherever possible, downregulated protein spots were cut from gels of control samples and up-regulated protein spots were cut from gels of treated samples. The strategy for the MS identification of proteins is presented in Supporting Information 1, Figure S2. Digest aliquots of $5 \mu \mathrm{L}$ were directly infused into an LTQ Orbitrap (Thermo Fisher Scientific, Bremen, Germany) mass spectrometer using a robotic nanoflow ion source TriVersa (Advion Biosciences, Ithaca, NY) as described in Lu et al. ${ }^{47}$ Survey spectra were acquired in four overlapping segments $(\mathrm{m} / \mathrm{z}$ $300-500,450-650,600-800,750-1350$ ) in selected ion monitoring (SIM) mode at the target resolution of 60000 (full width at half-maximum, fwhm) on an Orbitrap mass analyzer. Survey scans were followed by MS/MS of the four most intense precursors observed within the corresponding $\mathrm{m} / \mathrm{z}$ segment and were acquired on a linear ion trap mass analyzer. MS/MS spectra were converted to MASCOT generic format (.mgf) and searched against a nrNCBI database (6 857938 entries; December 2008) and against an EST database generated from 9736 F. sylvatica dormant bud ESTs (Leger, V.; Le Provost, G.; Plomion, C.; unpublished), 1149 cDNA sequences of subtractive libraries from P. citricola infected roots $^{48}$ and 64603 Fagus grandifolia ESTs from the Fagaceae Project (http://www. fagaceae.org) by MASCOT v. 2.2 software (Matrix Science Ltd., London, U.K.) installed on a local 2 CPU server. Mass tolerance for precursor ions was set to $10 \mathrm{ppm}$ and for fragment ions to $0.6 \mathrm{Da}$; up to two missed cleavages were allowed; fixed modification was carbamidomethylation of cysteine; variable modifications were oxidation of methionines and N-terminus acetylation of the intact protein. MASCOT hits were considered confident without further consideration if produced by matching of at least three MS/MS spectra with peptide ions scores above 20 or two spectra with scores higher than 40 . Identifications based on a single matched spectrum with a peptide ion score exceeding the value of 50 were considered borderline.

In parallel, MS/MS spectra were subjected to de novo interpretation by a modified version of PepNovo software. ${ }^{49}$ PepNovo was set to produce up to seven sequence candidates for each MS/MS spectrum. Only spectra whose interpretation produced sequences with PepNovo quality scores above 6.0 were considered. ${ }^{50}$ Peptide sequence candidates were then merged into a single MS BLAST query string. Searches were performed against an nr database at the Web-accessible server at http://genetics.bwh.harvard.edu/msblast. Statistical confi- 
dence of database searching hits was estimated according to MS BLAST scoring scheme, ${ }^{51}$ however, only considering high scoring segment pairs (HSP) with scores above 55 .

If no confident protein identification was reached, the remaining digest was subjected to LC-MS/MS analysis on LTQ or (where specified) LTQ Orbitrap mass spectrometer as described. ${ }^{49,52}$ LC-MS/MS data sets were processed as described in Junqueira et al. ${ }^{53}$ Briefly, MS/MS spectra were first filtered against a library of $\sim 15000$ nonannotated background MS/MS spectra using EagleEye software. ${ }^{54}$ Background spectra recognized by EagleEye were removed, while the remaining spectra were searched by MASCOT against nrNCBI and EST library using the settings described above. In parallel to stringent database searches, the MS/MS spectra remained from EagleEye filtering were submitted to de novo sequencing and sequence similarity searches as described above with the exception that the LC-MS/MS presets of MS BLAST were applied. ${ }^{53}$

\section{Results}

3.1. Infection of $F$. sylvatica Seedlings with the Root Pathogen $\boldsymbol{P}$. citricola. Infection symptoms following the inoculation with the root pathogen $P$. citricola were recorded at leaf level for the experiments in soil system and at root level for the experiments in liquid system. Root tip browning was observed after 4-6 days from inoculation, while leaf wilting of plants infected in soil system was recorded 7 days after inoculation (one day after the end of the flooding period) (Supporting Information 1, Figure S3b). In case of soil system infection, only one leaf was sampled from plants without symptoms when first wilting symptoms were recorded in the infected lot, allowing us to continue the record of above ground symptoms (Supporting Information 1, Figure S3a). Of the inoculated plants, $90 \%$ showed wilting symptoms within the first 2 weeks from inoculation and all except one had clear symptoms before 46 days ( 40 days from the end of the flooding period). All plants died within 2-3 days after showing first symptoms. Only two control plants exhibiting symptoms different from the infected plants died within this period (at 21 and 46 days from inoculation, respectively).

3.2. Identification of Proteins Affected by Pathogen Attack and Wounding. One-dimensional SDS-PAGE did not reveal consistent differences in abundance of low-soluble proteins between the infected and wounded plants and controls (data not shown).

2DE protein spots were considered regulated in response to the treatment applied when they exhibited both statistically significant differences and a fold variation that exceeded the spot-specific threshold of variation that could appear by chance alone in the study population (Supporting Information 2, pictures in Supporting Information 3). This method is a rather conservative approach for the identification of differential protein expression. We preferred such an approach for our experiments because it is restrictive in what concerns the number of false positives resulting from experiments performed on low number of replicates.

A total of 188 protein spots separated on 2DE gels (142 leaf proteins and 46 root proteins) significantly changed their abundance following root infection with P. citricola or wounding (Table 1). Of them, 129 were specifically regulated following pathogen attack, 37 specifically responded to wounding and 22 responded to both stressors. To identify and compare general and specific patterns of protein expression in response
Table 1. Overview of Protein Expression Regulation Following Infection with P. citricola and/or Wounding

\begin{tabular}{ccccc}
\hline specificity & infection & wound & both & total \\
\hline Leaves & 99 & 26 & 17 & 142 \\
Roots & 30 & 11 & 5 & 46
\end{tabular}

to root infection and leaf or root wounding, proteins were clustered on the basis of their fold regulation and expression patterns across all treatments (Supporting Information 1, Figure S6). Our approach represents a slight modification of the method suggested by Lippert et al. ${ }^{31}$ and can reveal patterns of protein expression independent of the absolute protein abundance and fold regulation. Cluster analysis revealed several patterns of protein expression regulation in response to infection and wounding, synthesized in Figure 1. Protein spots excised from 2DE gels were analyzed by tandem mass spectrometry as described in section 2.6. Despite the careful experiment design and 2DE gel analysis, among the proteins regulated from the root gels, we identified three proteins likely to belong to the pathogen (Supporting Information 2). Twenty spots were mixtures of two to six proteins. In some cases, a closer inspection of the spectra (computing of the spectral abundance factor ${ }^{55}$ and comparison of the relative abundance of precursor ions of the different protein components between control and treatment samples ${ }^{56}$ ) enabled the identification of the regulated proteins. However, in 11 cases, the spots were no longer available from both control and treatment gels and this analysis could not be performed. Rapid screening of all spots by direct infusion of digests into the mass spectrometer identified 17 plant proteins. Protein spots exhibiting most interesting patterns of expression in response to infection and/ or wounding were subsequently subjected to LC-MS/MS analysis. A further 15 and 36 of host's proteins were identified by LC-MS/MS on a hybrid LTQ-Orbitrap and an LTQ mass spectrometer, respectively. Of the 68 identified proteins representing 51 protein functions, four could only be identified in the EST database and another five by de novo sequencing and MS BLAST searches. Although good quality spectra were obtained for all spots analyzed on the hybrid LTQ-Orbitrap and LTQ mass spectrometers, 14 spots could not be identified most probably due to the limited similarity to the reference sequences available in the databases. Hereafter, spot numbers refer to numbers in Figure 1 and Table 2.

3.3. Defense Response against $\boldsymbol{P}$. citricola. Plants grown in liquid system responded to infection by the local regulation (roots) of 35 protein spots (23 up-regulated and 12 downregulated) and the systemic regulation (leaves) of 48 protein spots (31 up-regulated and 17 down-regulated). Protein expression regulation was temporally specific. Different sets of proteins were systemically regulated during early and late stages of infection (12 and 36 proteins, respectively). The local response during early and late stages of infection (consisting of 8 and 31 proteins, respectively) shared only four regulated proteins (three up-regulated and one down-regulated).

A higher number of 102 proteins were systemically regulated following infection in soil system, of which 65 were upregulated and 37 down-regulated. Of these, 34 (23 up-regulated, 7 down-regulated and 4 with opposite regulation) responded both in soil system and in liquid system experiments. Overall, similar proportions of the local (root) and systemic (leaves) response to infection consisted in up-regulation $(65 \%$ and $64 \%$, respectively) or down-regulation (35\% and $36 \%$, respectively) of protein abundance. 


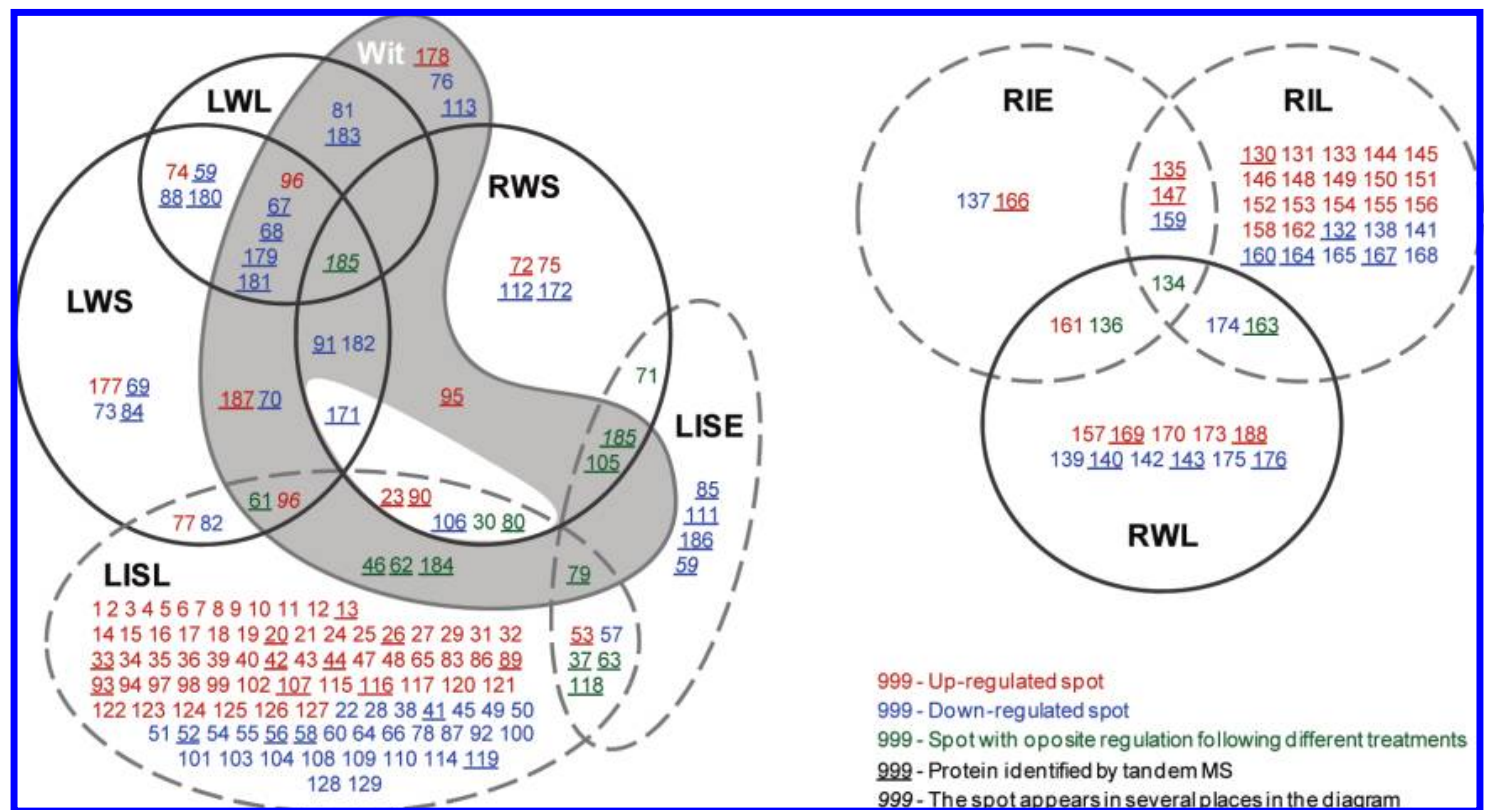

Figure 1. Venn diagram of protein spots exhibiting expression regulation following infection with $P$. citricola and/or wounding. Spot numbers are the same as in Supporting Information 2 and 3. Full lines, wound response; dashed lines, infection response; LISE, leaf infection systemic early; LISL, leaf infection systemic late; LWL, leaf wound local; LWS, leaf wound systemic; RWS, root wound systemic; Wit, Witness trees; RIE, root infection early; RIL, root infection late; RWL, root wound local.

Identified proteins regulated following pathogen infection were functionally classified into energy and metabolism, protein synthesis, folding and localization, secondary metabolism, signal transduction and stress and defense related proteins (Table 2).

3.4. Defense Response against Wounding. We observed significant changes in the abundance of 32 protein spots following root wounding (16 local, roots; and 16 systemic, leaves) and of 25 spots following leaf wounding (2 local, 13 systemic and 10 both local and systemic, all in leaves). Functionally, the regulated proteins covered all classes mentioned above (Table 2). Systemic response to the wounding of roots and of leaves shared only four protein spots (three downregulated and one up-regulated), all of them involved in carbohydrate metabolism.

Individuals "witnessing" wounding of the neighboring seedlings (denoted "witness tree" in Figure 1) also exhibited changes in protein abundance, a large part of them overlapping with the local or systemic response to infection or wounding (22 protein spots of which only three were specific) (Figure 1). Among them were proteins involved in primary metabolism and protection from oxidative stress and detoxification.

We found only limited evidence for a vertical asymmetry in the systemic response: two isoforms of $\beta$-D-galactoside galactohydrolase (spots 185, 186) slightly stronger up-regulated in leaves below the wounded leaf as compared to leaves above the level of the wounded leaf.

3.5. Overlaps in the $F$. sylvatica Response to Infection and Wounding. Local infection and wound-induced changes in protein abundance partly overlapped: five spots, of which three exhibited opposite directions of regulation in response to the two stressors. One of the later (spot 163) was identified as cytochrome-b5 reductase and was pathogen induced but wound repressed. Common responses between plant reaction to infection and to root or leaf wounding were also observed systemically (Figure 1). We identified eight proteins responsive to infection and root wounding involved in protein localization, energy, metabolism and defense as well as five proteins responsive to infection and leaf wounding of which two were involved in primary metabolism. Additionally, four regulated proteins were common among leaves from infected plants and leaves of witnessing plants, of which three were identified and involved in primary metabolism. However, most of the stressresponsive proteins $(93.1 \%)$ were stressor specific.

Roots and leaves expressed different sets of stress regulated proteins following both infection and wounding, in full accord with previous investigations at transcriptome level, which showed that plant response to different types of stress is largely organ-specific. $^{2}$

\section{Discussion}

4.1. Symptoms of $F$. sylvatica Infection with $P$. citricola. $F$. sylvatica seedlings infected with $P$. citricola exhibited root and leaf symptoms similar to those observed in other studies such as Fleischmann et al. ${ }^{20}$ In the liquid infection system, root tip necrosis was observed after 4-6 days from inoculation with $P$. citricola. Leaf wilting symptoms probably caused by the massive root loss during the necrotrophic stage of the infection were first recorded after 7 days post-inoculation, and continued to appear until 45 days in the soil infection system. After 48 days from the onset on the experiment, all but one plant had died. This high rate of mortality (99.5\%) of infected seedlings is in accord with previous reports on the high sensitivity of young $F$. sylvatica seedlings to infection with $P$. citricola as compared to 1 year old saplings. ${ }^{20}$

Among Phytophthora species, F. sylvatica is particularly sensitive to $P$. citricola, which severely damages plant's root system causing local necrosis. ${ }^{29,30}$ The pathogen exhibits a higher capacity to colonize $F$. sylvatica phloem tissues laterally as compared, for example, to species usually recognized as aggressive like $P$. cambivora and $P$. cinnamoni. ${ }^{24} P$. citricola causes $100 \%$ root rot in young seedlings as compared to $80 \%$ 


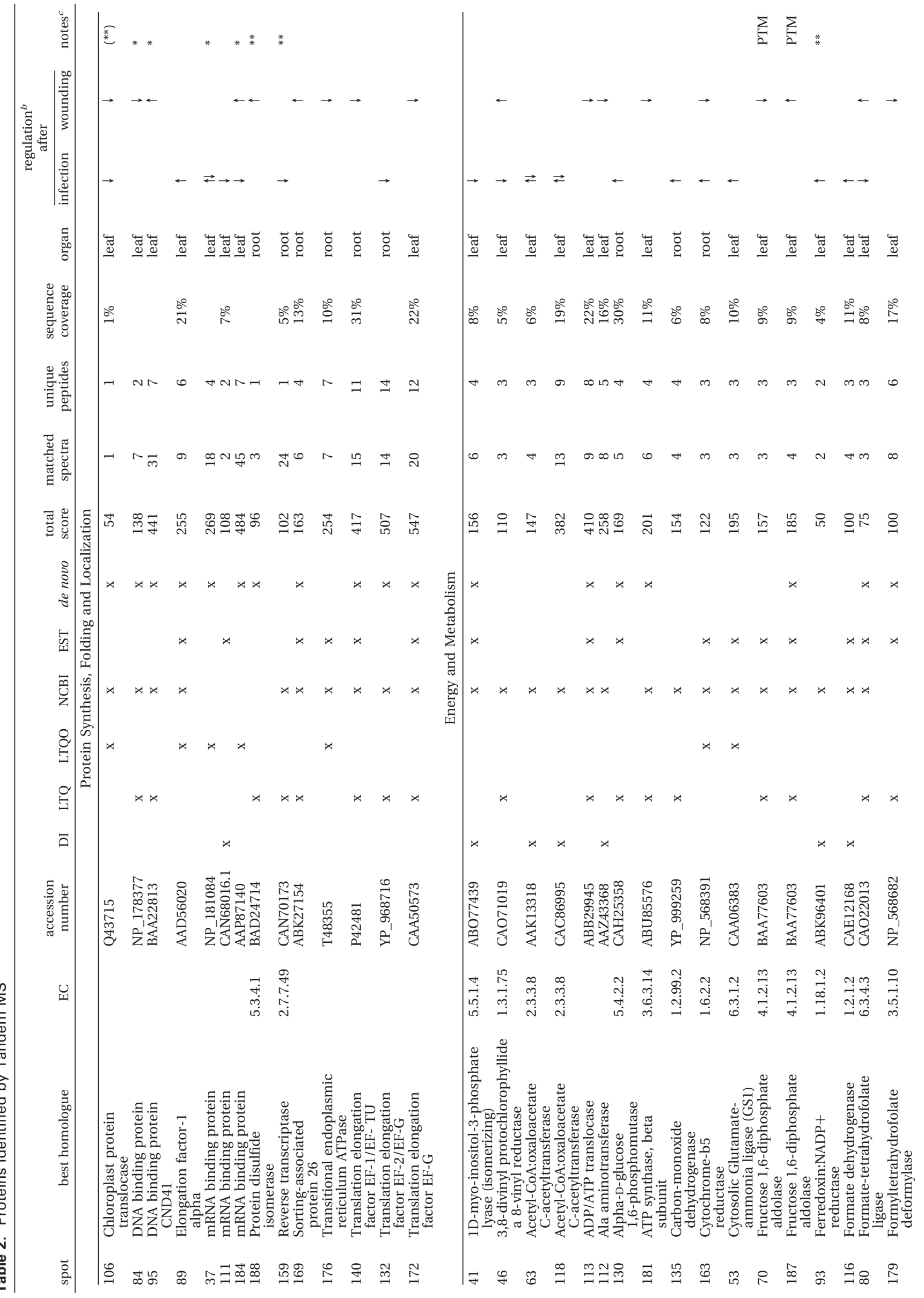




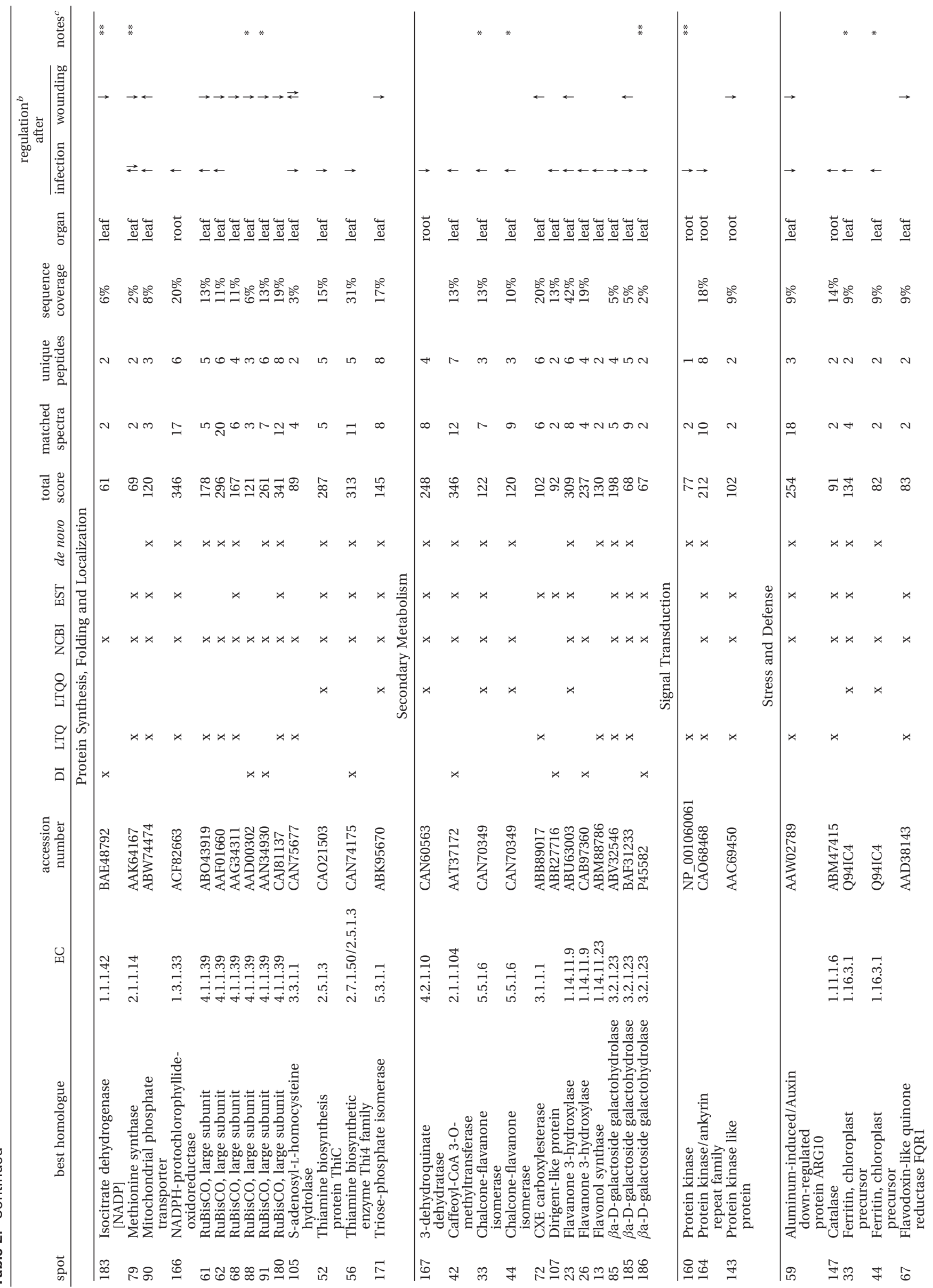




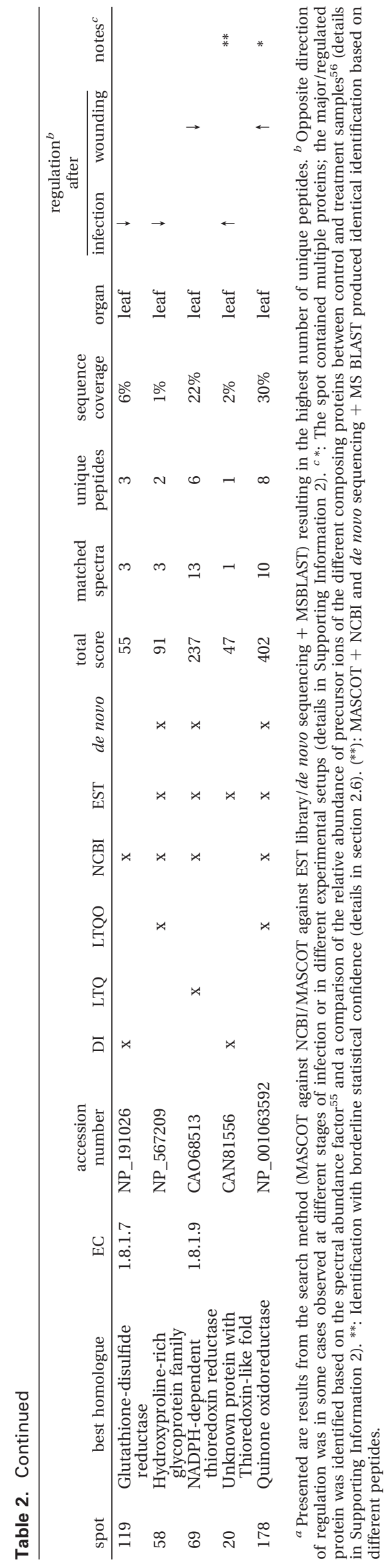

root damage produced by $P$. cambivora and less than $25 \%$ caused by Phytophthora syringae and P. undulata. ${ }^{20}$ The decrease of water use efficiency is also more severe in seedlings infected with $P$. citricola than in seedlings infected with any of the other three pathogens. ${ }^{20}$

Morphologically, the infection of $F$. sylvatica roots with $P$. citricola causes a significant reduction of the belowground biomass, that is, a reduction with almost $50 \%$ of the fine root length $(<0.5 \mathrm{~mm}$ diameter $) .{ }^{29,30}$ Above ground symptoms are generally unspecific, consisting mainly in chlorosis and wilting as, for example, in Juglans seedlings ${ }^{30}$ or Fagus. $^{20}$ At physiological level, the infection results in weakened rhizosphere activity and nutrient uptake $\mathrm{e}^{29,30}$ accompanied by a severe reduction of photosynthesis and transpiration. ${ }^{20}$ Plants were also shown to suffer from severe drought ${ }^{20}$ and oxidative stress ${ }^{30}$ symptoms.

4.2. Phytophthora-Induced Responses. Host response was initiated immediately after inoculation and involved regulation of general metabolism as well as synthesis of defense related proteins. Changes in the abundance of host proteins involved in transcription/translation, protein localization and signal transduction were observed both at the site of infection (spot 132, translation elongation factor; spots 160, 164, protein kinases) and systemically (spots 37, 111, 184, mRNA binding proteins; spot 89 , elongation factor- $1 \alpha$; spot 106 , chloroplast protein translocase), already at the early stages of infection. The amplitude of the local and systemic responses increased during the infection both in terms of the number of proteins and of their fold regulation. Such delays in hosts' reaction to late stages of infection, when the pathogen had entered necrotrophic growth and the damage is already very severe are typical for compatible interactions ${ }^{57}$ In inferring the biological significance of the host's proteome changes after pathogen attack, we need to consider that those changes might represent plant defense responses against the pathogen or might result from the manipulation of plant's metabolism by the invading pathogen. ${ }^{58}$

4.2.1. Local Response to Root Infection. At early stages of infection, host's response was relatively limited. The fold change of most early regulated proteins increased at later stages, and new proteins appeared regulated.

Catalase (spot 147) is the only defense related protein we identified in the local response. It is a salicylic acid (SA) inducible protein up-regulated during incompatible plantpathogen interactions. ${ }^{59}$ Its up-regulation at the site on infection suggests that reactive oxygen species (ROS) might be locally generated in the attempt to prevent pathogen invasion. ROS fulfill multiple roles in plant defense against pathogens, from direct killing of the pathogen in the hypersensitive response and inducing of systemic acquired resistance to cell wall fortification through oxidative cross-linking of cell wall glycoproteins.

Later on, few proteins involved in primary and secondary metabolism were regulated in infected roots. The glycolytic enzyme $\alpha$-D-glucose 1,6-phosphomutase (spot 130) and cytochrome b5 reductase (spot 163) involved in fatty acid metabo$\operatorname{lism}^{60}$ were up-regulated. An enzyme situated at the beginning of the Shikimate pathway (spot 167: 3-dehydroquinate dehydratase) was down-regulated in roots, although phenylpropanoid and flavonoid biosynthesis pathways were activated at systemic level.

Altogether, the local response to infection was weaker than the systemic one. The simultaneous separation of the plant and 
pathogen proteomes on the same gels in the case of infected roots resulted in a high spot overlap possibly hindering the identification of all regulated proteins. While this could have caused an underestimation of the local response, the functions of the regulated proteins point to an inefficient response to infection. An efficient defense against the pathogen would have triggered more SA induced reactions effective against biotrophic pathogens during the early stage of infection and jasmonic acid (JA) inducible defenses effective against necrotrophic pathogens at later stages. The protein functions locally regulated by $F$. sylvatica throughout the course of infection suggest that either the seedlings do not recognize the attack or their reaction is suppressed by the pathogen.

4.2.2. Systemic Response to Infection. Systemic changes in protein abundance partly differed between plants grown in soil and liquid systems, consistent with previous reports that plants' response to stress is largely determined by the physiological status and environmental/experimental conditions. ${ }^{2}$ However, the relatively larger number of proteins regulated in plants infected in soil system could also be due to the higher number of biological replicates which increased the power for the identification of differential expression.

A large part of the systemically regulated protein functions were related to energy and primary metabolism. Acetyl-CoA: oxaloacetate C-acetyltransferase is the major enzyme responsible for the synthesis of cytosolic acetyl-CoA and was reported to be activated during incompatible plant-pathogen interactions. ${ }^{61}$ Two isoforms of this enzyme (spots 63,118 ) were downregulated in leaves early after pathogen inoculation. However, seedlings grown in soil system up-regulated this protein function at late stages of infection probably in order to supply the acetyl-CoA necessary for fatty acids and sterols biosynthesis and for the activated phenylpropanoid and flavonoid biosynthesis pathways.

Down-regulation of 3,8-divinyl protochlorophyllide a 8-vinyl reductase (spot 46) decreases chlorophyll synthesis, which together with an increased RuBisCO degradation (spots 61, 62), suggests an overall decrease of carbon fixation at late stages of infection. This matches previous observations on the decrease of $F$. sylvatica photosynthesis after infection with P. citricola. ${ }^{20}$

Down-regulation of 1D-myo-inositol-3-phosphate lyase (spot 41) could either reduce the consumption of D-glucose-6phosphate in order to increase its availability for energy production through glycolysis and/or NADPH production through pentose phosphate pathway, or be a result of pathogen activity aiming to inhibit inositol metabolism and consequently production of myo-inositol hexakisphosphate involved in basic resistance to pathogens. ${ }^{62}$ The simultaneous up-regulation of $\alpha$-D-glucose 1,6-phosphomutase (spot 130, roots) and ferredoxin:NADP ${ }^{+}$reductase (spot 93, leaves) suggests that this is more likely an adjustment of metabolism for maintaining energy and NADPH levels. This could be a compensatory mechanism for the down-regulation of glutathione-disulfide reductase (spot 119). The latter could represent either a host defense mechanism leading to increased ROS levels, or an attempt of the pathogen to prevent the regeneration of the intracellular glutathione pool required for the activation of NPR1 which is subsequently responsible for the activation of PR genes. ${ }^{63}$

Decrease in the abundance of the auxin down-regulated ARG10 homologue (spot 59) could be an indication of increased auxin levels, which in turn is known to promote biotrophic pathogen invasion by suppression of SA-induced host defense and would thus help explaining the compatible character of the interaction. ${ }^{64}$ However, the protein was also downregulated following leaf wounding, which is known to generally antagonize auxin dependent gene regulation through the upregulation of a NPK1-like gene which negatively regulates auxin-dependent genes. ${ }^{65}$

Formate dehydrogenase (spot 116) is a mitochondrial, NADdependent enzyme involved in formate-dependent $\mathrm{O}_{2}$ uptake coupled to ATP synthesis, whose transcripts are induced in potato leaves by wounding ${ }^{66}$ and in Arabidopsis by SA, methyl jasmonate and during incompatible interaction with Alternaria brassicicola. ${ }^{59}$ The protein was up-regulated late in the leaves of infected seedlings. Another enzyme involved in the transfer of one-carbon units is formate-tetrahydrofolate ligase (spot 80). As previously reported for cucumber roots inoculated with Trichoderma asperellum, ${ }^{67}$ the enzyme was systemically downregulated during late stages of the infection.

Nitrogen remobilization has been described both in compatible and incompatible plant-pathogen interactions and interpreted either as a defense mechanism that deprives the pathogen of nutrients or as a pathogen induced manipulation of host metabolism meant to supply the pathogen with nutrients. ${ }^{6,69}$ Analysis of glumatate-ammonia ligase regulation during compatible and incompatible interactions of different Pseudomonas strains with Nicotiana tabacum suggested that in incompatible pathosystems the up-regulation of this enzyme has a defensive role. ${ }^{69}$ However, during a compatible interaction where the enzyme (spot 53) is up-regulated systemically rather than locally, we could speculate that the mechanism at work is a different one. As previously suggested, ${ }^{69}$ the pathogen could mimic a sink organ and cause a reallocation of plant resources to support its own growth.

Two enzymes involved in methionine biosynthesis and metabolism were systemically regulated in a time-dependent manner: methionine synthase (spot 79) was down-regulated at early stages of infection and up-regulated at late stages of infection, accompanied during the latter by a down-regulation of $S$-adenosyl-L-homocysteine hydrolase (spot 105, SHH). Methionine synthase is up-regulated during incompatible interactions of Arabidopsis thaliana and A. brassicicola ${ }^{59}$ and methionine is a precursor for furanocoumarins ${ }^{70}$ which show activity against Phytophthora infestans. ${ }^{71}$ Fungal elicitors from Phytophthora megasperma cause transcriptional activation of SHH in parsley. ${ }^{72}$ Since SHH regulates DNA methylation and thus gene expression, ${ }^{73}$ the complex pattern of regulation observed here could be designed to control the intracellular equilibrium of metabolites involved in transmethylation reactions ( $S$-adenosylhomocysteine and $S$-adenosylmethionine). Involvement of these mechanisms in pathogen defense is supported by previous observations that depletion of $\mathrm{SHH}$ expression increases tobacco resistance to virus infection. ${ }^{74}$ Moreover, $S$-adenosylmethionine is an intermediary in the synthesis of ethylene. ${ }^{75}$

Up-regulation of the mitochondrial phosphate transporter (spot 90) during advanced stages of infection suggests an increase in ATP synthesis similar to the one observed in Betula pendula following an ozone treatment which elicited plant responses comparable to those developed during incompatible interactions. ${ }^{76}$

Thiamine is a coenzyme of several enzymes involved in major metabolic pathways but is also an activator of disease resistance and SAR inducer in several species, ${ }^{77}$ mimicking incompatible interactions. ${ }^{78}$ Similarly to Populus response 
during an incompatible interaction with Melampsora laricipopulina, ${ }^{57}$ two enzymes on the thiamine biosynthetic pathway were systemically down-regulated at late stages of infection (spot 52, ThiC; spot 56, Thi4).

Three isoforms of $\beta$-D-galactoside galactohydrolase (spots 85 , $185,186)$ were down-regulated in leaves at early stages of infection. $\beta$-D-galactoside galactohydrolase is one of the major cell wall degrading enzymes involved in the metabolism of galactose-rich polymers and is usually induced in compatible interactions like that of Panax quinquefolius with the root pathogen Fusarium equiseti ${ }^{79}$ as well as in Phaseolus vulgaris by cell wall elicitors from Colletotrichum lindemuthianum. ${ }^{80}$

Among proteins with defense related functions systemically up-regulated at later stages of infection were ferritin (spots 33, 44), ferredoxin: $\mathrm{NADP}^{+}$reductase (spot 93) and a protein of the thioredoxin-like fold protein family (spot 20) involved in protein folding, protection from oxidative stress and pathogen defense. ${ }^{81}$ Ferritin contributes to the prevention of ROS production and increase of tolerance to pathogens, ${ }^{82}$ while ferredoxin: $\mathrm{NADP}^{+}$reductase (spot 93) is up-regulated during incompatible plant-pathogen interactions ${ }^{83}$ and involved in the protection from oxidative stress.

Hydroxyproline-rich glycoproteins are structural components of the cell wall oxidatively cross-linked for cell wall fortification in response to pathogen attack. ${ }^{84}$ Similarly, for example, to $A$. thaliana involved in a compatible interaction with Pseudomonas syringae, ${ }^{83}$ F. sylvatica seedlings systemically downregulated a member of this protein family (spot 58).

Several proteins involved in phenylpropanoid and flavonoid biosynthesis pathways were up-regulated during late stages of infection (spots 13, 23, 26, 33, 44, 42, 107). Phenylpropanoid and flavonoid biosynthesis pathways are known to be major parts of the nonspecific defense responses and their activation during compatible interactions with pathogens results in the accumulation of phenolic secondary metabolites with antioxidant and cell wall fortification roles including phytoalexins, lignins and salicylate. ${ }^{85,86}$ The activation of these pathways is stronger in the case of compatible plant-pathogen interactions, where the plants invest more resources in cell wall fortification and modulation of secondary metabolism. ${ }^{87} \mathrm{P}$. citricola induced a systemic activation of these pathways unlike glycoprotein elicitins from $P$. megasperma which induce HR and SAR in tobacco and increase local but not systemic $O$-methyltransferase (enzyme on the phenylpropanoid pathway) activity. ${ }^{88}$

As in the local response, the amplitude of the systemic response was relatively low at early stages of infection. Early and late stages of infection shared only a low number of proteins, most of them oppositely regulated. Among the latter were proteins involved in protein expression regulation (spot 37, mRNA binding protein) and primary metabolism (spot 79, methionine synthase; spots 63,118 , Acetyl-CoA: oxalacetate C-acetyltransferase). Early stages of susceptible interactions (e.g., soybean, Phytophthora sojae) do not consist in a hypersensitive reaction (HR) as incompatible interactions, but in a biotrophic phase during which the pathogen colonizes host cells and plant defenses are rather weak. ${ }^{89}$ This stage is followed by a necrotrophic phase associated with the apparition of necrotic lesions which can subsequently induce SAR. ${ }^{4}$ Gene expression patterns change during different stages of the compatible interaction reflecting this shift of the pathogen from the biotrophic to the necrotrophic stage during which activation of phenylpropanoid metabolism and SA-dependent defenses reaches a maximum. ${ }^{89}$ Such a transition could explain the high temporal specificity we observed in the protein regulation patterns induced by $P$. citricola at both local and systemic levels, all of the stress and defense related proteins except for catalase being regulated in F. sylvatica seedlings at late stages of infection. This supports the hypothesis that this host does not specifically recognize $P$. citricola or its defenses are suppressed by the pathogen and is in accord with previous observations that during compatible interactions defense related proteins are induced later and to a lower extent as compared to incompatible interactions. ${ }^{5}$ The results also confirm once more that the nature, amplitude and timing of host's response is pathosystem-specific. ${ }^{5}$

4.3. Wound-Induced Responses. Plant response to herbivore attack encompasses the defense response against the herbivore itself as well as against opportunistic pathogens. ${ }^{90}$ Direct and indirect defense mechanisms are elicited both by mechanical wounding and by herbivore-specific elicitors. ${ }^{91}$ Direct defense mechanisms confer the plant resistance to herbivores, ${ }^{8}$ while indirect mechanisms, consisting mainly of the secretion of volatile organic compounds (VOC), can attract parasitoids or predators of the herbivores ${ }^{9}$ and induce similar defense responses in neighboring unharmed plants. ${ }^{10}$ Proteomic analysis of root and leaf wounded as well as witnessing unharmed $F$. sylvatica seedlings revealed changes in protein expression underlying these mechanisms. Among the differentially expressed spots, we identified proteins involved in basic metabolism as well as typical stress responsive proteins, including some known to be involved in plant-pathogen interactions.

4.3.1. Root Wounding Response. Protein synthesis and localization were regulated after root wounding both in roots and in leaves (spots 95, 140, 172, 106). Moreover, SHH (spot 105), an enzyme that controls biological methylation reactions and thus has a role in the control of transcription, ${ }^{74}$ was upregulated in leaves following root wounding.

Mitochondrial phosphate transporter (spot 90) also accumulated in the leaves of root wounded seedlings, suggesting an increased requirement for ATP the same as after pathogen attack. The plants might try to compensate in this way the decrease in glycolysis shown by the down-regulation of triosephosphate isomerase (spot 171). This contrasts with the general down-regulation of ATP synthase (spot 181) after leaf wounding.

Protein processing at the level of Golgi apparatus was regulated in wounded roots. Sorting-associated protein 26 (spot 169) is part of the retromer complex, which plays an important role in the recycling of transmembrane receptors from endosomes to the trans-Golgi network. Protein disulfide isomerase (spot 188, PDI) is a molecular chaperone with thioredoxin domains residing in the endoplasmic reticulum. ${ }^{92}$ The spot was up-regulated in wounded roots, possibly as a result of the reticulum stress associated with the down-regulation of transitional reticulum ATPase (spot 176). The transfer of membranes from the endoplasmic reticulum to the Golgi apparatus is dependent on the transitional reticulum ATPase; therefore, the down-regulation of this protein is likely to induce accumulation of proteins and therefore endoplasmic reticulum stress for the release of which higher abundance of chaperones is necessary. Moreover, PDI was previously shown to be a target of NPR1 and part of the secretory machinery activated during SAR. ${ }^{93}$

Among proteins known to be involved in plant-pathogen interactions, flavanone 3-hydroxylase (spot 23) is an essential enzyme in the flavonoid pathway, while CXE carboxylesterase 
(spot 72) participates in alkaloid biosynthesis. These protein functions were up-regulated systemically after root wounding. Both pathways are recognized as typically induced during plant-pathogen interactions as well as following herbivore attack and wounding. ${ }^{94,95}$

4.3.2. Leaf Wounding Response. Amino acid, carbohydrate and energy metabolism were both locally and systemically regulated following leaf wounding. Several protein spots probably representing degradation products of RuBisCO (spots 61, $68,88,91,180$ ) decreased in abundance, suggesting a preservation of RuBisCO in wounded plants. This could be explained by the accumulaion of proteinase inhibitors following wounding. ${ }^{96}$

Isocitrate dehydrogenase (spot 183) involved in citric acid cycle and ATP synthase (spot 181) were down-regulated in wounded leaves. The abundance of the latter was also decreased in unharmed leaves of the leaf-wounded plants together with triose-phosphate isomerase (spot 171), a glycolytic enzyme known to be down-regulated after wounding in the apoplast of Medicago leaves. ${ }^{97}$ Another glycolytic enzyme, fructose 1,6-bisphosphate aldolase (spots 70, 187), was posttranslationally modified in distant unwounded leaves in a similar manner with that observed in Agrostis scambra and Agrostis stolonifera roots following heat stress. ${ }^{98}$ In this case, the authors could demonstrate that the shift on the 2DE gel was caused by phosphorylation and that higher levels of phosphorylation were associated with higher thermotolerance. Two other neighboring protein spots $(182,184)$ with similar behavior on the 2DE gels from leaf samples contained more than one protein; after a detailed investigation of the MS results, ${ }^{56}$ fructose 1,6-bisphosphate aldolase was identified as the protein changing in abundance (Supporting Information 2).

Formyltetrahydrofolate deformylase (spot 179) metabolizes 10 -formyltetrahydrofolate to tetrahydrofolate used in purine and amino acid synthesis and is essential for photorespiration. ${ }^{99}$ Similar to previous observations on proteins involved in photorespiration, ${ }^{100}$ the protein decreased in abundance following leaf wounding in both wounded and unwounded leaves.

A $\beta$-D-galactoside galactohydrolase isoform (spot 185) accumulated in all leaves of the wounded plants. Up-regulation of this enzyme in response to wounding was previously described for Papaya fruits ${ }^{101}$ and the protein is also known to be up-regulated in response to pathogens (see section 4.2).

Flavodoxin-like quinone reductase (spot 67), believed to be a detoxification enzyme, ${ }^{102}$ and NADPH-dependent thioredoxin reductase (spot 69), an enzyme involved in protection from oxidative stress, were down-regulated in leaf-wounded plants. This could be part of a defense mechanism against secondary infections with pathogens.

4.3.3. Witnessing Trees Response. Plant response to VOC has been scarcely investigated at proteome level. Investigations at transcriptome level suggested that, although no accumulation of defensive chemicals or transcripts occurs, Nicotiana attenuata transplanted close to clipped Artemisia tridentata tridentata is primed for defense against herbivores and accumulates trypsin proteinase inhibitors faster after herbivore attack. ${ }^{103}$ Nicotiana plants that witnessed clipping or herbivore attack on Artemisia have elevated levels of polyphenol oxidase activity and increased resistance to herbivores. ${ }^{104}$ Perception of volatile signals by Alnus glutinosa also causes an increased phenolic content and increased catalase and proteinase inhibitors activity. ${ }^{105}$

From our observations, the changes in the proteome of witnessing seedlings largely resemble those of the wounded plants themselves. This regards both proteins involved in general metabolism (glycolysis, spots 70, 187; citric acid cycle, spot 183; energy metabolism, spot 181; amino acid metabolism, spot 179) and proteins with potential defensive role (spots 185, 67). Moreover, based on the reduced degradation of RuBisCO (spots 61, 62, 68, 91) observed in witnessing seedlings, we could speculate that proteinase inhibitors are already active in these plants.

Notable exceptions from this pattern are a protein exhibiting opposite regulation as compared to wounded plants (spot 105, $S$-adenosyl-L-homocysteine hydrolase) and seven proteins specifically regulated in witnessing trees of which four were down-regulated (e.g., spot 79, Methionine synthase; spot 113, ADP/ATP translocase) and three were up-regulated (e.g., spot 46, 3,8-divinyl protochlorophyllide a 8-vinyl reductase; spot 178 , quinone oxidoreductase). The biological functions of those proteins cover amino acid metabolism, energy metabolism, chlorophyll biosynthesis and defense against oxidative stress, respectively.

4.3.4. Overlaps in Root and Leaf Wounding Responses. Wounding of roots and leaves induced partly overlapping changes in F. sylvatica local and systemic proteome (Figure 1). The overlap was larger between the local and systemic reactions to leaf wounding and rather limited between the reactions to leaf versus root wounding. While secondary metabolites and different proteins are known to accumulate after wounding locally and systemically, ${ }^{90}$ partial site specificity of plants' response to wounding has been already reported for other species. ${ }^{6}$

Systemic response to leaf and root wounding shared four proteins among which three were identified as participants to primary metabolism. The shared response regarded the reduction of glycolysis (spot 171, triose-phosphate isomerase) and activation of a cell wall degrading enzyme (spot 185, $\beta$-Dgalactoside galactohydrolase). The reduced RuBisCO degradation was more evident in plants with wounded leaves. Root wounding activated secondary metabolism related proteins including flavonoid and alkaloid biosynthesis (spots 23, 72), while leaf wounding inhibited oxidative stress protection and detoxification (spots 67,69), both putative defense mechanisms.

Local and systemic response to leaf wounding overlapped to a larger degree; wounded and unwounded leaves shared the signs of a reduced RuBisCO degradation, activation of cell wall degrading $\beta$-D-galactoside galactohydrolase (spot 185), as well as the down-regulation of ATP tetrahydrofolate synthesis and of two defense related proteins (spot 59, Auxin down-regulated protein ARG10; spot 67, Flavodoxin-like quinone reductase).

4.4. Overlaps in the $F$. sylvatica Response to Infection and Wounding. The overlap in the proteome changes induced by infection and wounding amounted to $16 \%$ of the spots regulated in response to $P$. citricola and $60 \%$ of the spots regulated in response to wounding (Figure 1). Out of the 18 shared spots, nine could be identified. Four of them are involved in protein localization (spot 106, chloroplast protein translocase), primary and secondary metabolism (spot 90, mitochondrial phosphate transporter; spot 23, Flavonone 3-hydroxylase) and stress reaction (spot 59, Auxin down-regulated protein ARG10) and were similarly regulated in response to infection and wounding. The remaining five proteins exhibited 
opposite regulation in response to the two stressors. Their function was associated with energy and metabolism (spot 80, Formate-tetrahydrofolate ligase; spot 61 , degradation product of RuBisCO; spot 105, S-adenosyl-L-homocysteine hydrolase; spot 163, Cytochrome-b5 reductase; spot 185, $\beta$-D-galactoside galactohydrolase).

The lack of differentiation in the regulation of secondary metabolism and stress and defense related proteins between infected and wounded plants, together with the differences in the modulation of plants' energy and metabolism related proteins after the two treatments can have two causes. One could be the lack of recognition of the pathogen and consequently the mobilization in the infected plants of unspecific defense mechanisms similar to those activated following wounding for the prevention of secondary infections by opportunistic pathogens. The other cause could be the manipulation of the host's metabolism by the invading pathogen, either directly through manipulation of host's gene expression or indirectly by mimicking a sink for the host's metabolites. Similarly to our observations, susceptible cultivars of Solanum were previously shown to induce a specific set of wound responsive genes in response to infection with P. infestans. ${ }^{106}$

\section{Conclusions}

Plants' needs to simultaneously cope with multiple environmental stressors have evolved in complex and effective defense mechanisms. Signaling and defense pathways against different types of aggressors like pathogens and herbivores are inter-regulated at different levels forming intricate networks designed to ensure a maximal chance of survival with a minimal investment of energy. This high level of inter-regulation was reflected at proteome level in F. sylvatica as a relatively high degree of co-regulation as well as opposite-regulation of protein abundance during compatible interaction with the root pathogen $P$. citricola and wounding.

The observed changes in protein abundance following root infection suggest a rather weak and inefficient defense against the pathogen. Adjustments of host energy and primary metabolism consisted mainly in decreased carbon fixation accompanied by a reallocation of nutrients. Defense reactions against the pathogen were mobilized late and consisted of rather unspecific mechanisms involving phenylpropanoid and flavonoid synthesis pathways and protection from oxidative stress. The observed patterns of protein regulation generally suggest either a lack of recognition or a suppression of host's defense reaction by the invading pathogen which seems to mimic a sink organ and consequently manipulate host's metabolism to support its own growth.

Wounding also caused adjustments of plant's metabolism and activated unspecific defense mechanisms most likely to prevent secondary infections with pathogens. Root and leaf wounding induced different adjustments of metabolism and defense mechanisms. Changes in protein abundance following wounding were mostly organ-specific, with local and systemic response to leaf wounding being strikingly similar. Root wounding produced local stress related to protein synthesis and processing, while leaf wounding mostly induced changes in energy and primary metabolism. Although both root and leaf wounding induced defenses against pathogens, the mechanisms involved were different, with root wounding inducing flavonoid and alkaloid synthesis pathways, and leaf wounding employing mostly ROS related mechanisms. Interestingly, secondary metabolism with pathogen defense related functions was activated by both root infection and root wounding suggesting once more that the nature of the unspecific defense response is specified by the site of where the stressor acts rather than the type of stressor.

Acknowledgment. The authors would like to thank Eliane Escher, Andrea Knaust and Dr. Henrik Thomas for excellent technical assistance as well as Dr. Anna Shevchenko and all members of Shevchenko group for support and stimulating discussions. We thank Dr. Mihai Valcu for his advice on statistical analyses and Prof. Gerhard Müller-Stark for promoting the proteomics projects in the group of Forest Genetics. We also thank Dr. Christophe Plomion for access to unpublished Fagus-ESTs generated by Dr. Valérie Leger, Dr. Grégoire Le Provost and Dr. Christophe Plomion from INRAPierroton within the Evoltree Network of Excellence funded by the EU. This work was supported by the German Research Foundation (DFG) as part of project A9 within the Collaborative Research Centre SFB 607. Work in Shevchenko laboratory was supported in part by the grant IR01GM070986-01A1 from NIH NIGMS.

Note Added after ASAP Publication. The genus name for Phytophthora syringae has been corrected in the Discussion for the version posted on the Web July 20, 2009.

Supporting Information Available: Supporting Information 1: methods for protein sample preparation, twodimensional gel electrophoresis, sample preparation for mass spectrometric analysis; Table S1, overview of wounding and infection experiments; Figure S2, strategy for the MS identification of proteins; Figure S3a, record of above ground symptoms following infection in soil system of F. sylvatica seedlings with the root pathogen $P$. citricola; Figure S3b, symptoms of infection with $P$. citricola in F. sylvatica; predictors of spot volume variation; Figure S4. effect displays plots of the minimal model for acidic gradient; Figure S5, effect displays plots of the minimal model for basic gradient; Figure S6. cluster analysis of F. sylvatica proteins regulated following root infection with $P$. citricola and/or wounding. Supporting Information 2: tables with details of proteins identified. Supporting Information 3: F. sylvatica 2DE spots differentially expressed following infection with the root pathogen $P$. citricola and wounding. This material is available free of charge via the Internet at http:// pubs.acs.org.

\section{References}

(1) Dong, X. Genetic dissection of systemic acquired resistance. Curr. Opin. Plant Biol. 2001, 4, 309-314.

(2) Kreps, J. A.; Wu, Y.; Chang, H. S.; Zhu, T.; Wang, X.; Harper, J. F. Transcriptome changes for Arabidopsis in response to salt, osmotic, and cold stress. Plant Physiol. 2002, 130, 2129-2141.

(3) Pieterse, C. M. J.; Van Loon, L. C. NPR1: the spider in the web of induced resistance signaling pathways. Curr. Opin. Plant Biol. 2004, 7, 456-464.

(4) Maleck, K.; Dietrich, R. A. Defense on multiple fronts: How do plants cope with diverse enemies. Trends Plant Sci. 1999, 4 (6), 215-219.

(5) Butt, Y. K.-C.; Lo, S. C.-L. Proteomics studies on plant-pathogen interaction in compatible and incompatile systems. Curr. Proteomics 2007, 4, 141-156.

(6) Bezemer, T. M.; van Dam, N. M. Linking aboveground and belowground interactions via induced plant defenses. Trends Ecol. Evol. 2005, 20 (11), 617-624.

(7) Schmidt, D. D.; Voelckel, C.; Hartl, M.; Schmidt, S.; Baldwin, I. T. Specificity in ecological interactions. Attack from the same lepidopteran herbivore results in species-specific transcriptional responses in two solanaceous host plants. Plant Physiol. 2005, 138 (3), 1763-1773.

L Journal of Proteome Research - Vol. xxx, No. xx, XXXX 
(8) Felton, G. W. Indigestion is a plant's best defense. Proc. Natl. Acad. Sci. U.S.A. 2005, 102 (52), 18771-18772.

(9) Arimura, G.; Kost, C.; Boland, W. Herbivore-induced, indirect plant defences. Biochim. Biophys. Acta 2005, 1734, 91-111.

(10) Dolch, R.; Tscharntke, T. Defoliation of alders (Alnus glutinosa) affects herbivory by leaf beetles on undamaged neighbours. Oecologia 2000, 125, 504-511.

(11) Kost, C.; Heil, M. Herbivore-induced plant volatiles induce an

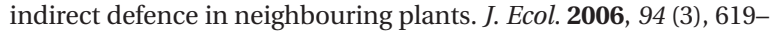
628.

(12) Tyler, B. M. Molecular basis of recognition between Phytophthora pathogens and their hosts. Annual Rev. Phytopathol. 2002, 40, $137-167$.

(13) Jung, T.; Blaschke, H.; Osswald, W. Involvement of soilborne Phytophthora species in Central European oak decline and the effect of site factors on the disease. Plant Pathol. 2000, 49, 706718.

(14) Vettraino, A. M.; Morel, O.; Perlerou, C.; Robin, C.; Diamandis, S.; Vannini, A. Occurrence and distribution of Phytophthora species in European chestnut stands, and their association with Ink Disease and crown decline. Eur. J. Plant Pathol. 2005, 111 (2), 169-180.

(15) Bunny, F. J. The biology, ecology and taxonomy of Phytophthora citricola in native plant communities in western Australia. Ph.D. Thesis, Murdoch University, Perth, Australia, 1996.

(16) Koike, S. T.; Browne, G. T.; Bhat, R. G.; Lee, R. C. M.; Tjosvold, S. A.; Buermeyer, K. Phytophthora leaf spot and foliar blight of Pieris japonica caused by Phytophthora citricola in California. Plant Dis. 2005, 89 (9), 1013-1013.

(17) Cahill, D. M.; McComb, J. A. A comparison of changes in phenylalanine ammonialyase activity, lignin and phenolic synthesis in the roots of Eucalyptus calophylla (field resistant) and E. marginata (susceptible) when infected with Phytophthora cinnamomi. Physiol. Mol. Plant Pathol. 1992, 40, 315-332.

(18) Okey, E. N.; Duncan, E. J.; Sirju-Charran, G.; T. N., S. Phytophthora canker resistance in cacao: Role of peroxidase, polyphenoloxidase and phenylalanine ammonia-lyase. I. Phytopathol. 1997, 145, 195-299.

(19) Doster, M. A.; Bostock, R. M. Quantification of lignin formation in almond bark in response to wounding and infection by Phytophthora species. Phytopathology 1988, 78 (4), 473-477.

(20) Fleischmann, F.; Schneider, D.; Matyssek, R.; Osswald, W. F. Investigations on net $\mathrm{CO}_{2}$ assimilation, transpiration and root growth of Fagus sylvatica infested with four different Phytophthora species. Plant Biol. 2002, 4 (2), 144-152.

(21) Balci, Y.; Halmschlager, E. Phytophthora species in oak ecosystems in Turkey and their association with declining oak trees. Plant Pathol. 2003, 52 (6), 694-702.

(22) Oudemans, P.; Forster, H.; Coffey, M. D. Evidence for distinct isozyme subgroups within Phytophthora citricola and close relationships with $P$. capsici and P. citrophthora. Mycol. Res. 1994, 98, 189-199.

(23) Ponchet, M.; Panabieres, F.; Milat, M. L.; Mikes, V.; Montillet, J. L.; Suty, L.; Triantaphylides, C.; Tirilly, Y.; Blein, J. P. Are elicitins cryptograms in plant-Oomycete communications? Cell. Mol. Life Sci. 1999, 56 (11-12), 1020-1047.

(24) Brasier, C. M.; Kirk, S. A. Comparative aggressiveness of standard and variant hybrid alder Phytophthoras, Phytophthora cambivora and other Phytophthora species on bark of Alnus, Quercus and other woody hosts. Plant Pathol. 2001, 50 (2), 218-229.

(25) Matheron, M. E.; Mircetich, S. M. Seasonal-variation in susceptibility of Juglans hindsii and Paradox rootstocks of English walnut trees to Phytophthora citricola. Phytopathology 1985, 75 (9), 970-972.

(26) Elhamalawi, Z. A.; Menge, J. A. Seasonal fluctuations in the extent of colonization of avocado plants by the stem canker pathogen Phytophthora citricola. J. Am. Soc. Hort. Sci. 1995, 120 (2), 157162.

(27) Brown, A. V.; Brasier, C. M. Colonization of tree xylem by Phytophthora ramorum, P. kernoviae and other Phytophthora species. Plant Pathol. 2007, 56 (2), 227-241.

(28) Werres, S. Influence of the Phytophthora isolate and the seed source on the development of beech (Fagus sylvatica) seedling blight. Eur. J. Forest Pathol. 1995, 25 (6-7), 381-390.

(29) Wang, Z. Y.; Göttlein, A.; Rodenkirchen, H.; Fleischmann, F.; $\mathrm{O} \beta$ wald, W. The Infuence of Phytophthora citricola on rhizosphere soil solution chemistry and the nutritional status of European beech seedlings. I. Phytopathol. 2003, 151, 365-368.

(30) Fleischmann, F.; Gottlein, A.; Rodenkirchen, H.; Lutz, C.; Osswald, W. Biomass, nutrient and pigment content of beech (Fagus sylvatica) saplings infected with Phytophthora citricola, P. cam- bivora, P. pseudosyringae and P. undulate. Forest Pathol. 2004, 34 (2), 79-92.

(31) Lippert, D.; Chowrira, S.; Ralph, S. G.; Zhuang, J.; Aeschlian, D.; Ritland, C.; Ritland, K.; Bohlmann, J. Conifer defense against insects: Proteome analysis of Sitka spruce (Picea sitchensis) bark induces by mechanical wounding or feeding by white pine weevils (Pissodes strobi). Proteomics 2007, 7, 248-270.

(32) Görg, A.; Weiss, W.; Dunn, M. J. Current two-dimensional electrophoresis technology for proteomics. Proteomics 2004, 4 (12), 3665-3685.

(33) Liska, A. J.; Shevchenko, A. Expanding the organismal scope of proteomics: Cross-species protein identification by mass spectrometry and its implications. Proteomics 2003, 3 (1), 19-28.

(34) Jung, T.; Cooke, D. E. L.; Blaschke, H.; Duncan, J. M.; Osswald, W. Phytophthora quercina sp nov., causing root rot of European oaks. Mycol. Res. 1999, 103, 785-798.

(35) Schubert, R.; Bahnweg, G.; Nechwatal, J.; Jung, T.; Cooke, D. E. L.; Duncan, J. M.; Muller-Starck, G.; Langebartels, C.; Sandermann, H.; Osswald, W. Detection and quantification of Phytophthora species which are associated with root-rot diseases in European deciduous forests by species-specific polymerase chain reaction. Eur. J. Forest Pathol. 1999, 29 (3), 169-188.

(36) Terce-Laforgue, T.; Huet, J.-C.; Permollet, J.-C. Biosynthesis and secretion of cryptogein, a protein elicitor secreted by Phytophthora cryptogea. Plant Physiol. 1992, 98, 936-941.

(37) Valcu, C. M.; Schlink, K. Efficient extraction of proteins from woody plant samples for two-dimensional electrophoresis. Proteomics 2006, 6 (14), 4166-4175.

(38) Valcu, C. M.; Schlink, K. Reduction of proteins during sample preparation and two-dimensional gel electrophoresis of woody plant samples. Proteomics 2006, 6 (5), 1599-1605.

(39) Shepherd, S. J.; Van West, P.; Gow, N. A. R. Proteomic analysis of asexual development of Phytophthora palmivora. Mycol. Res. 2003, 107 (4), 395-400.

(40) R-Development-Core-Team, R: A language and environment for statistical computing, R Foundation for Statistical Computing: Vienna, Austria, http://www.R-project.org, 2006.

(41) Brock, G.; Pihur, V.; Datta, S.; Datta, S. clValid: Validate Cluster Results. $R$ package version 0.5-2, 2006.

(42) Meyer, D.; Zeileis, A.; Hornik, K. vcd: Visualizing categorical data. $R$ package version $1.0-5,2007$.

(43) Fox, J. effects: Effect Displays for Linear and Generalized Linear Models. $R$ package version 1.0-9, 2006.

(44) Pinheiro, J.; Bates, D.; DebRoy, S.; Sarkar, D. nlme: Linear and nonlinear mixed effects models. R package version 3.1-77, 2006.

(45) Pinheiro, J.; Bates, D. M. Mixed Effects Models in S and S-Plus; Springer: New York, 2002.

(46) Shevchenko, A.; Tomas, H.; Hsavlis, J.; Olsen, J. V.; Mann, M. Ingel digestion for mass spectrometric characterization of proteins and proteomes. Nat. Protoc. 2006, 1 (6), 2856-2860.

(47) Lu, A.; Waanders, L. F.; Almeida, R.; Li, G.; Allen, M.; Cox, J.; Olsen, J. V.; Bonaldi, T.; Mann, M. Nanoelectrospray peptide mapping revisited: Composite survey spectra allow high dynamic range protein characterization without LCMS on an orbitrap mass spectrometer. Int. J. Mass Spectrom. 2007, 268 (2-3), 158-167.

(48) Schlink, K. Identification and characterization of differentially expressed genes from Fagus sylvatica roots after infection with Phytophthora citricola. Plant Cell Rep. 2009, 28, 873-882.

(49) Waridel, P.; Frank, A.; Thomas, H.; Surendranath, V.; Sunyaev, S.; Pevzner, P.; Shevchenko, A. Sequence similarity-driven proteomics in organisms with unknown genomes by LC-MS/MS and automated de novo sequencing. Proteomics 2007, 7, 2318-2329.

(50) Frank, A.; Pevzner, P. PepNovo: de novo peptide sequencing via probabilistic network modeling. Anal. Chem. 2005, 77 (4), 964973.

(51) Habermann, B.; Oegema, J.; Sunyaev, S.; Shevchenko, A. The power and the limitations of cross-species protein identification by mass spectrometry-driven sequence similarity searches. $\mathrm{Mol}$. Cell. Proteomics 2004, 3, 238-249.

(52) Charneau, S.; Junqueira, M.; Costa, C. M.; Pires, D. L.; Fernandes, 1. S.; Bussacos, A. C.; Sousa, M. V.; Ricart, C. A. O.; Shevchenko, A.; Teixeira, A. R. L. The saliva proteome of the blood-feeding insect Triatoma infestans is rich in platelet-aggregation inhibitors. Int. J. Mass Spectrom. 2007, 268 (2-3), 265-276.

(53) Junqueira, M.; Spirin, V.; Balbuena, T. S.; Thomas, H.; Adzhubei, I.; Sunyaev, S.; Shevchenko, A. Protein identification pipeline for the homology-driven proteomics. L. Proteomics 2008, 71 (3), 346356.

(54) Junqueira, M.; Spirin, V.; Balbuena, T. S.; Waridel, P.; Surendranath, V.; Kryukov, G.; Adzhubei, I.; Thomas, H.; Sunyaev, S.; Shevchenko, A. Separating the wheat from the chaff: unbiased 
filtering of background tandem mass spectra improves protein identification. L. Proteome Res. 2008, 7 (8), 3382-3395.

(55) Jin, J.; Cai, Y.; Yao, T.; Gottschalk, A. J.; Florens, L.; Swanson, S. K.; Gutierrez, J. L.; Coleman, M. K.; L. Workman, J.; Mushegian, A.; P. Washburn, M.; Conaway, R. C.; Conaway, J. A mammalian chromatin remodeling complex with similarities to the yeast INO80 complex. L. Biol. Chem. 2005, 280 (50), 41207-41212.

(56) Shevchenko, A.; Valcu, C. M.; Junqueira, M. Tools for exploring the proteomosphere. J. Proteomics 2009, 72 (2), 137-144.

(57) Rinaldi, C.; Kohler, A.; Frey, P.; Duchaussoy, F.; Ningre, N.; Couloux, A.; Wincker, P.; Thiec, D. L.; Fluch, S.; Martin, F.; Duplessis, S. Transcript profiling of poplar leaves upon infection with compatible and incompatible strains of the foliar rust Melampsora larici-populina. Plant Physiol. 2007, 144, 347-366.

(58) Kaffarnik, F. A. R.; Jones, A. M. E.; Rathjen, J. P.; Peck, S. C. Effector proteins of the bacterial pathogen Pseudomonas syringae alter the extracellular proteome of the host plant, Arabidopsis thaliana. Mol. Cell. Proteomics 2009, 8, 145-156.

(59) Schenk, P. M.; Kazan, K.; Wilson, I.; Anderson, J. P.; Richmond, T.; Somerville, S. C.; Manners, J. M. Coordinated plant defense responses in Arabidopsis revealed by microarray analysis. $\underline{\text { Proc. }}$. Natl. Acad. Sci. U.S.A. 2000, 97 (21), 11655-11660.

(60) Bagnaresi, P.; Mazars-Marty, D.; Pupillo, P.; Marty, F.; Briat, J.-F. Tonoplast subcellular localization of maize cytochrome b5 reductases. Plant I. 2000, 24 (5), 645-654.

(61) Suh, M. C.; Yi, S. Y.; Lee, S.; Sim, W.-S.; Pai, H. S.; Choi, D. Pathogen-induced expression of plant ATP:citrate lyase. FEBS Lett. 2001, 488, 211-212.

(62) Murphy, A. M.; Otto, B.; Brearley, C. A.; Carr, J. P.; Hanke, D. E. A role for inositol hexakisphosphate in the maintenance of basal resistance to plant pathogens. Plant J. 2008, 56, 638-652.

(63) Foyer, C. H. Redox homeostasis and antioxidant signaling: a metabolic interface between stress perception and physiological responses. Plant Cell 2005, 17, 1866-1875.

(64) Spoel, S. H.; Dong, X. Making sense of hormone crosstalk during plant immune responses. Cell Host Microbe 2008, 3, 348-351.

(65) Cheong, Y. H.; Chang, H.-S.; Gupta, R.; Wang, X.; Zhu, T.; Luan, S. Transcriptional profiling reveals novel interactions between wounding, pathogen, abiotic stress, and hormonal responses in Arabidopsis. Plant Physiol. 2002, 129, 661-677.

(66) Hourton-Cabassa, C.; Ambard-Bretteville, F.; Moreau, F.; de Virville, J. D.; Rémy, R.; de Francs-Small, C. C. Stress induction of mitochondrial formate dehydrogenase in potato leaves. Plant Physiol. 1998, 116, 627-635.

(67) Segarra, G.; Casanova, E.; Bellido, D.; Odena, M. A.; Oliveira, E.; Trillas, I. Proteome, salicylic acid, and jasmonic acid changes in cucumber plants inoculated with Trichoderma asperellum strain T34. Proteomics 2007, 7, 3943-3952.

(68) Tavernier, V.; Cadiou, S.; Pageau, K.; Lauge, R.; Reisdorf-Cren, M.; Langin, T.; Masclaux-Daubresse, C. The plant nitrogen mobilization promoted by Colletotrichum lindemuthianum in Phaseolus leaves depends on fungus pathogenicity. L. Exp. Bot. 2007, 58 (12), 3351-3360.

(69) Pageau, K.; Reisdorf-Cren, M.; Morot-Gaudry, J.-F.; MasclauxDaubresse, C. The two senescence-related markers, GS1 (cytosolic glutamine synthetase) and GDH (glutamate dehydrogenase), involved in nitrogen mobilization, are differentially regulated during pathogen attack and by stress hormones and reactive oxygen species in Nicotiana tabacum L. leaves. L. Exp. Bot. 2006, 57 (3), 547-557.

(70) Somssich, I. E.; Hahlbrock, K. Pathogen defence in plants - a paradigm of biological complexity. Trends Plant Sci. 1998, 3, 8690.

(71) Shim, S.-H.; Kim, J.-C.; Jang, K. S.; Choi, G. J. Anti-oomycete activity of furanocoumarins from seeds of Psoralea corylifolia against Phytophthora infestans. Plant Pathol. J. 2009, 25 (1), 103107.

(72) Kawalleck, P.; Plesch, G.; Hahlbrock, K.; Somssich, I. E. Induction by fungal elicitor of S-adenosyl-L-methionine synthetase and S-adenosyl-L-homocysteine hydrolase mRNAs in cultured cells and leaves of Petroselinum crispur. Proc. Natl. Acad. Sci. U.S.A. 1992, 89, 4713-4717.

(73) Tanaka, H.; Masuta, C.; Uehara, K.; Kataoka, J.; Koiwai, A.; Noma, M. Morphological changes and hypomethylation of DNA in transgenic tobacco expressing antisense RNA of the S-adenosylL-homocysteine hydrolase gene. Plant Mol. Biol. 1997, 35, 981986.

(74) Masuta, C.; Tanaka, H.; Uehara, K.; Kuwata, S.; Koiwai, A.; Noma, M. Broad resistance to plant viruses in transgenic plants conferred by antisense inhibition of a host gene essential in S- adenosylmethionine-dependent transmethylation reactions. Proc. Natl. Acad. Sci. U.S.A. 1995, 92, 6117-6121.

(75) Ravanel, S.; Gakiere, B.; Job, D.; Douce, R. The specific features of methionine biosynthesis and metabolism in plants. Proc. Natl. Acad. Sci. U.S.A. 1998, 95, 7805-7812.

(76) Kiiskinen, M.; Korhonen, M.; Kangasjärvi, J. Isolation and characterization of cDNA for a plant mitochondrial phosphate translocator (Mpt1): ozone stress induces Mpt1 mRNA accumulation in birch (Betula pendula Roth). Plant Mol. Biol. 1997, 35, 271-279.

(77) Ahn, I.-P.; Kim, S.; Lee, Y.-H. Vitamin B1 functions as an activator of plant disease resistance. Plant Physiol. 2005, 138, 1505-1515.

(78) Ahn, I.-P.; Kim, S.; Lee, Y.-H.; Suh, S.-C. Vitamin B1-induced priming is dependent on hydrogen peroxide and the NPR1 gene in Arabidopsis. Plant Phvsiol. 2007, 143, 838-848.

(79) Goswami, R. S.; Punja, Z. K. Molecular and biochemical characterization of defense responses in ginseng (Panax quinquefolius) roots challenged with Fusarium equiseti. Physiol. Mol. Plant Pathol. 2008, 72, 10-20.

(80) Hughes, R. K.; Dickerson, A. G. Modulation of elicitor-induced Chitinase and $\beta$-1,3-glucanase activity by hormones in Phaseolus vulgaris. Plant Cell Physiol. 1991, 32 (6), 853-861.

(81) Kürkcüoglu, S.; Degenhardt, J.; Lensing, J.; Al-Masri, A. N.; Gau, A. E. Identification of differentially expressed genes in Malus domestica after application of the non-pathogenic bacterium Pseudomonas fluorescens Bk3 to the phyllosphere. L. Exp. Bot. 2007, 58 (3), 733-741.

(82) Deak, M.; Horvath, G. V.; Davletova, S.; Török, K.; Sass, L.; Vass, I.; Barna, B.; Kiraly, Z.; Dudits, D. Plants ectopically expressing the iron-binding protein, ferritin, are tolerant to oxidative stress damage and pathogens. Nat. Biotechnol. 1999, 17, 192-196.

(83) Jones, A. M. E.; Thomas, V.; Bennett, M. H.; Mansfield, J.; Grant, M. Modifications to the Arabidopsis defense proteome occur prior to significant transcriptional change in response to inoculation with Pseudomonas syringae. Plant Phvsiol. 2006, 142, 1603-1620.

(84) Broekaert, W. F.; Delaure, S. L.; De Bolle, M. F. C.; Cammuel, B. P. A. The role of ethylene in host-pathogen interactions. Annu. Rev. Phytopathol. 2006, 44, 393-416.

(85) Hückelhoven, R. Cell wall-associated mechanisms of disease resistance and susceptibility. Annu. Rev. Phytopathol. 2007, 10127, 101-127.

(86) Ralph, S.; Park, J. Y.; Bohlmann, J.; Mansfield, S. D. Dirigent proteins in conifer defense: gene discovery, phylogeny and differential wound- and insect-induced expression of a family of DIR-like genes in spruce (Picea spp.). Plant Mol. Biol. 2006, 60, 21-40.

(87) Fofana, B.; Banks, T. W.; McCallum, B.; Strelkov, S. E.; Cloutier, $\mathrm{S}$. Temporal gene expression profiling of the wheat leaf rust pathosystem using cDNA microarray reveals differences in compatible and incompatible defence pathways. Int. J. Plant Genomics 2007, 2007, 1-13.

(88) Cordelier, S.; de Ruffray, P.; Fritig, B.; Kauffmann, S. Biological and molecular comparison between localized and systemic acquired resistance induced in tobacco by a Phytophthora megasperma glycoprotein elicitin. Plant Mol. Biol. 2003, 51, 109118.

(89) Moy, P.; Qutob, D.; Chapman, B. P.; Atkinson, I.; Gijzen, M. Patterns of gene expression upon infection of soybean plants by Phytophthora sojae. Mol. Plant-Microbe Interact. 2004, 17 (10), 1051-1062.

(90) de Bruxelles, G. L.; Roberts, M. R. Signals regulating multiple responses to wounding and herbivores. Crit. Rev. Plant Sci. 2001, 20 (5), 487-521.

(91) Kessler, A.; Baldwin, I. T. Plant responses to insect herbivory: The emerging molecular analysis. Annu. Rev. Plant Biol. 2002, 53, 299328.

(92) Houston, N. L.; Fan, C.; Xiang, Q.-Y.; Schulze, J.-M.; Jung, R.; Boston, R. S. Phylogenetic analyses identify 10 classes of the protein disulfide isomerase family in plants, including singledomain protein disulfide isomerase-related proteins. Plant Physiol. 2005, 137, 762-778.

(93) Wang, D.; Weaver, N. D.; Kesarwani, M.; Dong, X. Induction of protein secretory pathway is required for systemic acquired resistance. Science 2005, 308, 1036-1040.

(94) Treutter, D. Significance of flavonoids in plant resistance and enhancement of their biosynthesis. Plant Biol. 2005, 7, 581-591.

(95) Vázquez-Flota, F.; Carrillo-Pech, M.; Minero-García, Y.; MirandaHam, M. d. L. Alkaloid metabolism in wounded Catharanthus roseus seedlings. Plant Physiol. Biochem. 2004, 42 (7-8), 623628. 
(96) Sembdner, G.; Parthier, B. The biochemistry and the physiological and molecular actions of jasmonates. Annu. Rev. Plant Physiol. Plant Mol. Biol. 1993, 44, 569-589.

(97) Soares, N. C.; Francisco, R.; Vielba, J. M.; Ricardo, C. P.; Jackson, P. A. Associating wound-related changes in the apoplast proteome of Medicago with early steps in the ROS signal-transduction pathway. I. Proteome Res. 2009, 8 (5), 2298-2309.

(98) $\mathrm{Xu}, \mathrm{C}$.; Huang, B. Root proteomic responses to heat stress in two Agrostis grass species contrasting in heat tolerance. L. Exp. Bot 2008, 59 (15), 4183-4194.

(99) Collakova, E.; Goyer, A.; Naponelli, V.; Krassovskaya, I.; III, J. F. G. Hanson, A. D.; Shachar-Hill, Y.; Matzke, M. A. Arabidopsis 10formyl tetrahydrofolate deformylases are essential for photorespiration. Plant Cell 2008, 20, 1818-1832.

(100) Delessert, C.; Wilson, I. W.; van der Straeten, D.; Dennis, E. S.; Dolferus, R. Spatial and temporal analysis of the local response to wounding in Arabidopsis leaves. Plant Mol. Biol. 2004, 55, 165181 .

(101) Karakurt, Y.; Huber, D. J. Characterization of wound-regulated cDNAs and their expression in fresh-cut and intact papaya fruit during low-temperature storage. Postharvest Biol. Technol. 2007, 44, 179-183.
(102) Laskowski, M. J.; Dreher, K. A.; Gehring, M. A.; Abel, S.; Gensler, A. L.; Sussex, I. M. FQR1, a novel primary auxin-response gene, encodes a flavin mononucleotide-binding quinone reductase. Plant Physiol. 2002, 128, 578-590.

(103) Kessler, A.; Halitschke, R.; Diezel, C.; Baldwin, I. T. Priming of plant defense responses in nature by airborne signaling between Artemisia tridentata and Nicotiana attenuata. Oecologia 2006, 148, 280-292.

(104) Karban, R.; Maron, J.; Felton, G. W.; Ervin, G.; Eichenseer, H. Herbivore damage to sagebrush induces resistance in wild tobacco: evidence for eavesdropping between plants. OIKOS 2003, 100, 325-332.

(105) Tscharntke, T.; Thiessen, S.; Dolch, R.; Boland, W. Herbivory, induced resistance, and interplant signal transfer in Alnus glutinosa. Biochem. Syst. Ecol. 2001, 29, 1025-1047.

(106) Ros, B.; Thummler, F.; Wenzel, G. Comparative analysis of Phytophthora infestans induced gene expression in potato cultivars with different levels of resistance. Plant Biol. 2005, 7 (6), 686-693.

PR900456C 